QRS duration measured by 12-lead ECG in RA pts treated with TOFA (table 1). However, an increase in $P Q$ interval duration was observed $(p=0,04)$. There were significantly decrease of mean $\operatorname{HR}(p<0,003)$, increase of QRS duration $(p<0,03)$, QTc $(p<0.03)$, night QTc $(p<0,02)$ in 24 h ECG ambulatory recording. $H R, P Q$, QTc duration were changed independently of beta-blockers therapy. The number of pts with QTc $\geq 440 \mathrm{~ms}$ increased from $11 \%$ to $21 \%(p>0.05)$. A change in QTc duration correlated negatively with dynamics of DAS 28 , SDAI $(r=-0,4, p<0,05)$, DM $(r=0,5, p<0,02), d B P(r=-0,4, p<0,04)$. There were also significantly increase number of ventricular premature beats $(p<0,03)$.

Table 1. ECG characteristics of pts with RA treated with TOFA

\begin{tabular}{lcc}
\hline & Baseline & After 12 months \\
\hline 12-lead ECG & $71[64 ; 81]$ & \\
Heart rate, bpm & $133[126 ; 131]$ & $69[61 ; 78]$ \\
PQ, ms & $83[79 ; 89]$ & $150[130 ; 160]^{\star}$ \\
QRS, ms & $421[406 ; 434]$ & $84[80 ; 91]$ \\
QTc, ms & $78[70 ; 84]$ & $410[398 ; 420]$ \\
24 h ECG & $82[73 ; 91]$ & $74[65 ; 80]^{\star}$ \\
Heart rate, bpm & $409[402 ; 425]$ & $85[73 ; 92]^{\star}$ \\
QRS, ms & $414[400 ; 434]$ & $415[406 ; 427]^{*}$ \\
QTc, ms & $18(66)$ & $420[408 ; 437]^{*}$ \\
QTc night, ms & $14[7 ; 50]$ & $22(78)$ \\
VPB pts, $n$ (\%) & $280[15 ; 3423]^{\star}$ \\
Ventricular premature beats, $n$ &
\end{tabular}

Data are presented in median values and IR (unless otherwise noted), ${ }^{*} \mathrm{p}<0,05$ before and after TOFA treatment (nonparametric paired Wilcoxon test).

Conclusions: A significant decrease in HR and an increase in QRS, night QTc interval duration, number of ventricular premature beats by $24 \mathrm{~h}$ ECG were observed in RA pts treated with tofacitinib (TOFA) during 12-month follow-up. QTC duration correlated with dynamic of disease activity, DM type 2 and diastolic BP. Disclosure of Interest: None declared

DOI: 10.1136/annrheumdis-2017-eular.5119

\section{THU0149 A CLINICAL AND PATHOLOGICAL CHARACTERIZATION OF METHOTREXATE-ASSOCIATED LYMPHOPROLIFERATIVE DISORDERS IN PATIENTS WITH RHEUMATOID ARTHRITIS}

K. Nakano ${ }^{1}$, A. Nawata ${ }^{1,2}$, S. Nakayamada ${ }^{1}$, S. Iwata $^{1}$, K. Hanami $^{1}$, S. Kubo ${ }^{1}$ I. Miyagawa ${ }^{1}$, M. Yoshikawa ${ }^{1}$, K. Saito ${ }^{1}$, Y. Tanaka ${ }^{1} .{ }^{1}$ The First Department of Internal Medicine; ${ }^{2}$ Department of Pathology, University of Occupational and Environmental Health, Japan, Kitakyushu, Japan

Background: Methotrexate (MTX) is used as an anchor drug for the treatment of rheumatoid arthritis (RA). Patients with RA have a modestly increased risk of developing lymphoproliferative disorders (LPD). Furthermore, although sometimes spontaneous regression occurs after withdrawal of MTX, LPD developed during the treatment with MTX is broadly defined as MTX-associated LPD (MTX-LPD). Objectives: To characterize the risk factors concerning MTX-LPD and to consider optimal treatment after occurrence of LPD in patients with RA.

Methods: We retrospectively evaluated 51 RA patients with LPD from 2006 to 2015 in our institution. MTX-LPD patients were divided into two groups; regressive LPD after MTX cessation ( $N=27)$ and persistent LPD though MTX was tapered $(\mathrm{N}=24)$, and the clinical characteristics, pathology and treatment outcomes were compared. EBV infection and IL-6 receptor (IL-6R) expression were analyzed by in situ hybridization and immunohistochemistry.

Results: There was no significant difference in disease duration, stage, disease activity of RA, the positive rate of Epstein-Barr virus-encoded small RNAs, EBERs (42.7 vs $50.0 \%$ ) and treatment with TNF-inhibitors (40.7 vs $45.8 \%$ ) between regressive LPD and persistent LPD. Age of LPD onset (59.1 vs 68.3), CRP (2 vs $5 \mathrm{mg} / \mathrm{dl}$ ) and the weekly MTX dose (10.9 vs $8.4 \mathrm{mg} / \mathrm{w}$ ) significantly differed between the groups. Of note, IL-6R was highly expressed in both group (75.0 vs $66.7 \%$ ). Among regressive LPD, 3 patients developed DLBCL later. persistent LPD showed poorer prognosis and worse mortality than regressive LPD. An older age and anemia were poor prognostic factors. Of 51 patients, $41 \%$ achieved sustained low disease activity (LDA) with other DMARDs except MTX. Nine of 10 patients refractory to DMARDs were controlled by tocilizumab (TCZ) and kept LDA.

Conclusions: Taken together, it seems unreasonable to be lump the persistentgroup into the same category as MTX-LPD. The high expression rate of IL-6R and the high responsiveness to TCZ suggest that IL-6/IL-6R is likely to play a role in the development of LPD in patients with RA.

Disclosure of Interest: K. Nakano: None declared, A. Nawata: None declared, S. Nakayamada: None declared, S. Iwata: None declared, K. Hanami: None declared, S. Kubo Speakers bureau: Bristol-Myers, I. Miyagawa: None declared, M. Yoshikawa: None declared, K. Saito: None declared, Y. Tanaka Grant/research support from: Mitsubishi-Tanabe, Takeda, Daiichi-Sankyo, Chugai, Bristol-Myers, MSD, Astellas, Abbvie, Eisai, Consultant for: Abbvie, Chugai, Daiichi-Sankyo, Bristol-Myers, Mitsubishi-Tanabe, Astellas, Takeda, Pfizer, Teijin, Asahi-kasei, YL Biologics, Sanofi, Janssen, Eli Lilly, GlaxoSmithKline, Speakers bureau: Abbvie, Chugai, Daiichi-Sankyo, Bristol-Myers, Mitsubishi-Tanabe, Astellas, Takeda, Pfizer, Teijin, Asahi-kasei, YL Biologics, Sanofi, Janssen, Eli Lilly, GlaxoSmithKline DOI: 10.1136/annrheumdis-2017-eular.4660

\section{THU0150 OPTIMIZING COMORBIDITY RISK MANAGEMENT IN RA BY TRANSLATING A NURSE-LED INTERVIEW INTO AN EASILY INTERPRETABLE TRAFFIC LIGHT SYSTEM}

K. Krüger ${ }^{1}$, R. Eder ${ }^{2}$, C. Müller ${ }^{3}$, R. Hecker ${ }^{3} \cdot{ }^{1}$ Rheumatologisches Praxiszentrum St. Bonifatius, München; ${ }^{2}$ Rheumapraxis am Spitaltor, Deggendorf; ${ }^{3}$ Abbvie Deutschland Gmbh \& Co. Kg, Wiesbaden, Germany

Background: Due to its inflammatory nature, rheumatoid arthritis (RA) is associated with a variety of comorbidities and individual risk factors [1]. The benefit of a nurse-led programme on RA comorbidity management has been reported recently [2].

Objectives: To describe a new assessment tool for patient risk management and report the difference between structured versus expert guided assessment following standard of care in a construct-validation cohort.

Methods: The ongoing cluster randomized multicentre study ERIKO is longitudinally assessing individual risk profiles of patients with RA in Germany. The aim of this study is to test the benefit of applying a nurse-led scoring algorithm for individual risk profiles followed by a structured patient consultation (active arm) as compared to local standard of care.

The ERIKO-Score was calculated by rating validated assessment tools and treatment guidelines and translating their outcome into a three-level ordinal score defined by the categories low, intermediate or high risk, including nominal weights for risk management (e.g. condition is being treated with goals achieved or not). Scores were interpreted numerically by rating categories with 0,1 and 2 points, respectively.

We included cardiovascular (CV) risk (ESC-guideline), infection risk (RABBIT risk calculator), vaccination status (guideline), fracture risk (FRAX), tooth status (PSI), depression- (PHQ-9) and health-related quality of life (hrQoL, RAID). The same risk categorization was prompted in all centres at the screening visit without providing the rating tools.

This analysis compares $\mathrm{SOC}$ ratings from the screening visit (month zero) with the baseline ERIKO-scores at month three in the active arm. No statistical hypothesis testing was performed in this analysis.

Results: This analysis included 283 patients from 31 centres specialized in rheumatology care randomized to the active study arm. $82.3 \%$ were female with a mean age of 57.8 years (sd 12.1) and a mean DAS28 of 2.6 (sd 1.1). The mean total ERIKO-Score was slightly higher at baseline as compared to applying the scoring algorithm on SOC ratings at the screening visit ( $5.33+-1.95$ vs. 4.32 +- 2.61, respectively, table 1). The discrepancy was mainly driven by CV risk, vaccination status, tooth status and depression risk, that were more often rated worse by applying the ERIKO score than by SOC, while infection- and fracture risk were more frequently rated lower by the ERIKO-Score (table 2). The strongest discrepancy between SOC ratings and ERIKO-Score ( $\Delta=2$ points) were observed for tooth status ( $\mathrm{N}=54), \mathrm{CV}$ risk $(\mathrm{N}=25)$ and vaccination status $(\mathrm{N}=25)$ (table 2). SOC ratings were strongly based on expert opinion with the most frequently cited tools being vaccination guidelines $(38.9 \%)$, bone mineral density measurement (BMD) $(39.6 \%)$ and RABBIT-infection risk-score (23.1\%).

\begin{tabular}{|c|c|c|c|c|c|c|c|c|}
\hline \multicolumn{2}{|l|}{$N=283^{\circ}$} & \multicolumn{5}{|c|}{ Ordinal Risk Rating } & \multicolumn{2}{|c|}{ Numeric interpretation } \\
\hline Dimension & $\begin{array}{l}\text { missing } \\
{[\%(N)]}\end{array}$ & $\begin{array}{l}\text { Low } \\
{[\%(N)]}\end{array}$ & \multicolumn{2}{|c|}{$\begin{array}{c}\text { Intermediate } \\
{[\%(N)]}\end{array}$} & \multicolumn{2}{|c|}{$\begin{array}{l}\text { High } \\
{[\%(N)]}\end{array}$} & $\begin{array}{l}\text { Median } \\
\text { (IQR) }\end{array}$ & Mean (sd) \\
\hline$\overline{C V}$ risk & $9.2(26)$ & $27.9(79)$ & \multicolumn{2}{|c|}{$26.5(75)$} & \multicolumn{2}{|c|}{$36.4(103)$} & $1(2)$ & $1.1(0.80)$ \\
\hline $\begin{array}{l}\text { Vaccination } \\
\text { status }\end{array}$ & $9.2(26)$ & $15.9(45)$ & \multicolumn{2}{|c|}{$50.5(143)$} & \multicolumn{2}{|c|}{$24.4(69)$} & $1(1)$ & $1.1(0.66)$ \\
\hline Infection risk & $9.2(26)$ & $79.9(226)$ & \multicolumn{2}{|c|}{$10.2(29)$} & \multicolumn{2}{|c|}{$0.7(2)$} & $0(0)$ & $0.1(0.36)$ \\
\hline $\begin{array}{l}\text { Risk of major } \\
\text { osteoporotic } \\
\text { fracture }\end{array}$ & $9.9(28)$ & $527(149)$ & \multicolumn{2}{|c|}{$32.9(93)$} & \multicolumn{2}{|c|}{$4.6(13)$} & $O(1)$ & $0.5(0.59)$ \\
\hline Tooth status & $11.3(32)$ & $5.3(15)$ & \multicolumn{2}{|c|}{$55.1(156)$} & \multicolumn{2}{|c|}{$28.3(80)$} & 1 (1) & $1.3(0.56)$ \\
\hline $\begin{array}{l}\text { Depression } \\
\text { risk }\end{array}$ & $9.2(26)$ & $46.3(131)$ & \multicolumn{2}{|c|}{$39.6(112)$} & \multicolumn{2}{|c|}{$4.9(14)$} & $O(1)$ & $0.5(0.60)$ \\
\hline hrQol & $9.2(26)$ & $33.9(96)$ & \multicolumn{2}{|c|}{$47.3(134)$} & \multicolumn{2}{|c|}{$9.5(27)$} & $1(1)$ & $0.7(0.64)$ \\
\hline \multicolumn{9}{|c|}{$\mathrm{n}=26$ without data at baseline } \\
\hline \multicolumn{7}{|c|}{$\begin{array}{l}\text { Table } 2 \text { Discrepancy between ERIKO-Score and ratings following SOC (baseline vs. screening) } \\
\Delta=1 \text { or } 2 \text { points (total) }\end{array}$} & \multicolumn{2}{|c|}{$\begin{array}{l}\Delta=2 \text { points } \\
\text { (low vs. high) }\end{array}$} \\
\hline \multicolumn{2}{|l|}{ Dimension } & \multicolumn{2}{|c|}{$\begin{array}{c}\text { No } \\
\text { difference }\end{array}$} & \multicolumn{2}{|c|}{$\begin{array}{l}\text { SOC risk } \\
\text { lower }\end{array}$} & $\begin{array}{l}\text { SOC risk } \\
\text { higher } \\
{[\%(N)]}\end{array}$ & $\begin{array}{l}\text { SOC risk } \\
\text { lower } \\
{[\%(N)]}\end{array}$ & $\begin{array}{l}\text { SOC risk } \\
\text { higher } \\
{[\%(N)]}\end{array}$ \\
\hline \multicolumn{2}{|l|}{ CV risk } & $\frac{[\%(N)]}{350(99)}$ & $35.0(99)$ & \multicolumn{2}{|c|}{$44.2(125)$} & $10.2(29)$ & $8.5(24)$ & $0.4(1)$ \\
\hline \multicolumn{2}{|c|}{ Vaccination status ${ }^{\circ}$} & \multicolumn{2}{|c|}{$34.6(98)$} & \multicolumn{2}{|c|}{$38.5(109)$} & $17.7(50)$ & $7.4(21)$ & $1.4(4)$ \\
\hline \multicolumn{2}{|l|}{ Infection risk ${ }^{\circ}$} & $63.6(1$ & & 6.011 & & $21.2(60)$ & 0 & $3.2(9)$ \\
\hline $\begin{array}{l}\text { Risk of major o } \\
\text { fracture }\end{array}$ & oporotic & 36.811 & & 15.214 & & $38.9(110)$ & $1.4(4)$ & $3.5(10)$ \\
\hline Tooth status" & & $18.4 !$ & & $47.7(1)$ & & $23.3(66)$ & $15.5(44)$ & $3.5(10)$ \\
\hline Depression rist & & 48.411 & & 30.718 & & $11.7(33)$ & $3.2(9)$ & $3.2(9)$ \\
\hline hrQol $^{\circ}$ & & 64.611 & & 18.015 & & $14.1(40)$ & $2.1(6)$ & $0.4(1)$ \\
\hline
\end{tabular}

Conclusions: A nurse-led comorbidity risk assessment in rheumatology practices seems feasible. Applying the ERIKO-Score based on validated tools led to a 